\title{
Asymmetric visual representation of sex from facial appearance
}

\author{
Marco Gandolfo ${ }^{1 *}$ and Paul E. Downing ${ }^{2}$
}

1. Donders Institute for Brain, Cognition, and Behaviour, Radboud University, Nijmegen, $\mathrm{NL}$

2. School of Human and Behavioural Sciences, Bangor University, Bangor, UK

* Correspondence concerning this article should be addressed to Marco Gandolfo

e-mail: marco.gandolfo@donders.ru.nl

Keywords: social vision; face perception; sex perception; visual search; search asymmetry 


\begin{abstract}
We efficiently infer others' traits from their faces, and these inferences powerfully shape our social behaviour. Here, we investigated how sex is represented in facial appearance. Based on previous findings from sex-judgment tasks, we hypothesised that the perceptual encoding of sex is not balanced but rather polarised: for the processes that generate a sex percept, the default output is "male", and the representation of female faces extends that of the male, engaging activity over unique detectors that are not activated by male faces. We tested this hypothesis with the logic of Treisman's studies of visual search asymmetries, predicting that observers should more readily detect the presence of female faces amongst male distractors than vice versa. Across three experiments ( $N=32$ each), each using different face stimuli, we confirmed this prediction in response time and sensitivity measures. We apply GIST analyses to the face stimuli to exclude that the search asymmetry is explained by differences in image homogeneity. These findings demonstrate a property of the coding that links facial appearance with a significant social trait: the female face is coded as an extension of a male default. We offer a mechanistic description of perceptual detectors to account for our findings and posit that the origins of this polarised coding scheme are an outcome of biased early developmental experience.
\end{abstract}




\section{Introduction}

Research in social vision seeks to understand the visual processes underpinning everyday social behaviour. Many studies have sought to understand how observers extract and use the socially relevant cues about others' age, race, sex, health, emotion, direction of attention, and other states and traits that are visible in facial appearance (Adams et al., 2010; Todorov, 2017). Among these, the perception of sex ${ }^{1}$ has been of particular interest. Sex is considered one of the "big three" social dimensions on which observers tend to categorise others at first encounter (along with age and race; Carter, 1944; Ito \& Urland, 2003). Evolutionary and social psychology suggest drivers that encourage categorisation by sex, for example evaluating the fitness of potential mates (Little et al., 2001; Perrett et al., 1998), or activating associated information in semantic memory (Eagly \& Mladinic, 1989; Skrypnek \& Snyder, 1982; Stroessner, 1996). Here, we report new findings showing that the visual coding of sex from adult faces is not balanced symmetrically, but rather polarised, such that "female" is coded as an extension of a "male" default.

Adult human faces are sexually dimorphic with respect to shape, texture, and colouration. Accordingly, behavioural tests reveal observers' capacity to judge sex on the basis of face properties including overall shape (Bruce et al., 1993; Nestor \& Tarr, 2008), contrast (Russell, 2009; Russell et al., 2017), and pigmentation (Bruce \& Langton, 1994; Nestor \& Tarr, 2008), and from patterns of facial motion (Berry, 1991). Disrupting holistic processing or configural information interferes with sex judgments, suggesting a contribution of whole-face representations (Baudouin \& Humphreys, 2006; De Gutis et al., 2012; Zhao \& Hayward, 2010). Yet reliable sex judgments are also possible from individual face parts (Brown \& Perrett, 1993; Schyns et al., 2002; Yamaguchi et al., 2013) or reveal a strong reliance on specific parts (Dupuis-Roy et al., 2009; Faghel-Soubeyrand et al., 2019; Macrae \& Martin, 2007; Schyns et al., 2002). Finally, adaptation to a face of one sex shifts the subjective male/female boundary, so that subsequent ambiguous faces favour the other sex (e.g. Webster et al., 2004). Face adaptation persists over manipulations of the relative position, orientation, and size of adapter and test faces, excluding explanations based on low-level visual mechanisms (Afraz et al., 2010; Bestelmeyer et al., 2008; Webster \& MacLeod, 2011). Together, this evidence shows that cues to sex are multiplexed in the appearance of the face, and high-level, face-specific representations offer several routes for an observer to make a sex judgment.

One key finding is that observers tend to default to a "male" judgment, especially when information about the face is ambiguous. The male bias is found in judgments of photographs (Watson et al., 2016), artificial faces (Armann \& Bülthoff, 2012), face profile silhouettes (Davidenko, 2007), and illusory faces (Wardle et al., 2022), and for

\footnotetext{
1 In line with current guidance (e.g. https://orwh.od.nih.gov/sex-gender), we use "sex" to refer to a categorical distinction between images of people's faces and bodies, and "gender" in reference to our participants.
} 
adults' judgments of both child and infant faces (Boisferon et al., 2019; Tskhay \& Rule, 2016). This pattern appears in several tasks, such as binary male/female choices, continuous judgments (how male/female?), or comparisons (which is more male?) about faces drawn from a morph series (e.g. Armann \& Bülthoff, 2012; Graf \& Wichmann, 2002; Watson et al., 2016; Wild et al., 2000).

An evolutionary account of the male bias emphasises the survival implications of errors in person categorisation: if unknown males are more likely to present a physical threat than females, then it may be less risky to err in favour of judging male (Haselton et al., 2015; Haselton \& Buss, 2000). Instead from a mechanistic perspective, which is our focus here, one possibility is that the bias results from post-perceptual decision making: visual representations of the face are balanced with respect to sex, and the male bias is introduced when a judgment is required. Here we test the deeper possibility, that the male bias reveals asymmetries in the perceptual coding of the face: a polarised rather than a balanced representation (cf. Proctor \& Cho, 2006; Watson et al., 2016). That is, for the mental processes that encode sex, the default output is "male", and "female" is determined only in the presence of additional perceptual evidence. This implies that while male and female faces share many properties in common, the female face is positively coded by additional features or properties, relative to the male (cf Wardle et al., 2022). Conversely, males, as the default percept, have fewer additional unique features that distinguish them from females. Importantly, we refer to features not in the everyday sense of face parts, but rather in terms of the components of mental representations.

To test this proposal, we adopted the approach of Treisman's search asymmetry studies (Treisman \& Gormican, 1988; Treisman \& Souther, 1985). Visual search performance is sometimes asymmetrical, depending on whether a given item is a target or a distractor. For example, converging lines are found more efficiently amongst parallel pairs than vice versa, and search for an ellipse amongst circles is more efficient than the converse. Treisman suggested that the coding of some visual dimensions is organised around canonical values and extensions of those values. An ellipse, for example, is encoded as an extension of a canonical circle. While both kinds of stimuli activate detectors for the canonical property (e.g. circularity), deviations are further positively coded by additional activity over selective detectors that are not tuned to the default property. The asymmetry in search performance favouring deviating targets arises because it reflects a presence (an increment in activity) which is more readily detected than an absence (Neisser, 1963; Rajsic et al., 2020).

Similar logic has been adapted to understand the encoding of complex emergent stimulus properties (Enns \& Rensink, 1990, 1991; Hulleman et al., 2000; Kristjánsson \& Tse, 2001; Sun \& Perona, 1996ab), including properties of the face (Becker et al., 2011; Becker \& Rheem, 2020). Recently, we also applied this logic to examine the visual encoding of sex from body shape, revealing a consistent and stimulus-invariant search 
advantage for female over male body targets (Gandolfo \& Downing, 2020). Together, these findings demonstrate the suitability of the search asymmetry approach to study the coding of complex stimuli including objects, bodies and faces.

Here we report three visual search studies testing the hypothesis that sex is coded asymmetrically, such that the female face is represented as an extension of the male default. Female targets should be easier to find amongst male distractors than vice versa, as measured by search rates or by detection accuracy (d prime). To ensure that any such effect is generalisable, we tested three kinds of face stimuli: 1) artificially rendered face images; 2) face profile silhouettes, generated from real face source images; and 3) face photographs from four different image databases.

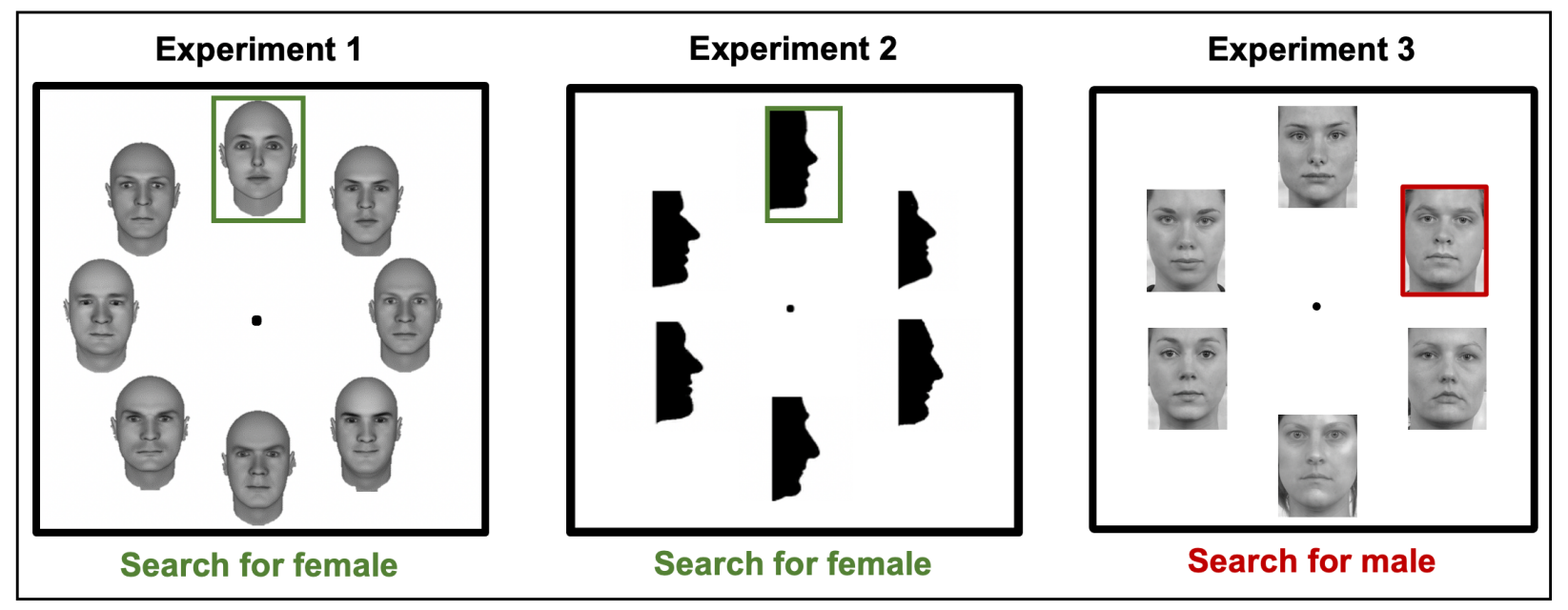

Figure 1. Example stimuli for Experiment 1 (frontal FaceGen faces), Experiment 2 (profile silhouettes) and Experiment 3 (frontal face photographs, here from the Radboud Faces database - Langner et al., 2010). Search set sizes included 1, 2, 4, or 8 items in Experiment 1, and 1, 2, 4, or 6 items in Experiments 2 and 3. Coloured outlines highlight the target items in each sample display; these were not included in the actual experiments. Task instructions were provided at the start of each block; sample instructions are provided here for illustration only.

\section{Methods}

\section{Participants}

Participants were students at Bangor University who took part in return for course credit in a research methods module. No individual participant took part in more than one experiment. The procedures were approved by the Research Ethics Committee of Bangor University's School of Psychology, and participants provided written informed consent. The target sample size for each experiment was set at $\mathrm{N}=32$ following our previous work using very similar methods to identify search asymmetries for human 
body stimuli (Gandolfo \& Downing, 2020). Based on the size of the search asymmetry found in our previous work ( $\mathrm{d} z=0.51)$, with a power analysis we estimated that a sample of 32 participants would be sufficient to detect an effect of a similar size with at least $80 \%$ power. In Experiments 1 and 3 we recruited a gender-balanced sample including 16 females in each (age data unavailable for Experiment 1; mean age $20 \pm 1.2$ years for Experiment 3). Experiment 2 included 23 females (mean age $20 \pm 2$ years). Participants with overall mean response times or accuracy (averaged across conditions) of $>2.5 \mathrm{SD}$ below or above the group mean for that experiment were considered outliers. Their data were excluded and new participants were tested to replace them to reach a sample size of $\mathrm{N}=32$. (For Experiment 2, two additional participants were tested in this phase due to an oversight and their data are included in the present analyses). Exclusion numbers were as follows: 1 in Experiment 1; 3 in Experiment 2; 1 in Experiment 3.

\section{Stimuli and apparatus}

Experiments were administered using the Psychtoolbox package (Brainard \& Vision, 1997; Pelli \& Vision, 1997) running in Matlab (MATLAB Release 2012b, The MathWorks, Inc., Natick, Massachussets, US) on an Apple iMac computer. Viewing distance was approximately $60 \mathrm{~cm}$ from the screen but was not fixed. The face images we used are illustrated in Figure 1. Images from Experiments 1 and 2 are available to download at this link (https://osf.io/ucq2g/). Images from Experiment 3 are available from the maintainers of those face databases (see below).

\section{Experiment 1}

The faces for Experiment 1 were generated using FaceGen Modeller Version 3.1 (Singular Inversions; Toronto, ON, Canada). Previous studies of face perception have extensively used computer-generated stimuli (e.g. Oosterhof \& Todorov, 2008) because they can be manipulated to vary realistically in their high-level social characteristics (sex, age, facial expression, race) while controlling for other low-level visual factors.

We created two sets of stimuli with 40 faces ( 20 males, 20 females) in each set. Facial expression was set to neutral and the ethnicity was Caucasian for all the faces. The faces were presented without hair. The FaceGen software allows manipulation of sex while keeping the identity and some other dimensions of a face constant (such as expression). Accordingly, the male faces generated for one set were identity-matched with the female faces for the other set. Each participant was randomly assigned to perform the experiment with one of the two sets. The faces were scaled to $180 \times 180 \mathrm{px}$ each, and converted to greyscale.

\section{Experiment 2}


In Experiment 2, we used face profile silhouettes following Davidenko's approach (Davidenko, 2007; Davidenko et al., 2012). These stimuli capture the global shape of the face without including confounding internal features such as colour or texture. Previous studies show that face silhouttes are visually processed in many ways like face photographs and provide enough information for accurate age estimation and sex judgments (Davidenko, 2007; Davidenko et al., 2012).

The final sample of silhouettes included 12 images of males and 12 images of females, rendered at $180 \times 180 \mathrm{px}$. Details of the creation, selection, and pixel-level analysis of these stimuli are in the Supplemental Materials.

\section{Experiment 3}

In Experiment 3, we selected images of neutral-expression faces from four face photograph databases: KDEF (Calvo \& Lundqvist, 2008; Goeleven et al., 2008); Nimstim (Tottenham et al., 2009); Radboud (Langner et al., 2010); and Stirling (http://pics.psych.stir.ac.uk/). From each database, 12 males and 12 females were chosen. The final sample of stimuli included 96 photographs, 48 male and 48 female faces, which were presented at a size of $180 \times 140$ px.

We matched the selected images for spatial frequency and luminance using the SHINE Matlab toolbox (Willenbockel et al., 2010, see Supplemental Materials).

\section{Design and Procedure}

The design and procedure closely followed Gandolfo \& Downing (2020). Participants were instructed in different blocks either to search for a female face amongst male face distractors, or a male face amongst female distractors. The design included four blocks, each comprising 128 trials (Experiments 1 and 2) or 120 trials (Experiment 3); in two blocks the target was male, and in two female. The four blocks were presented in a counterbalanced order (MFFM or FMMF, equally across participants) with a short break between blocks. In Experiments 1 and 2, within blocks, the trial orders were block randomised such that each chunk of 16 trials consisted of two trials each from the crossing of target (present, absent) by set size. In Experiment 3 , each chunk of 32 trials consisted of a counterbalanced combination of source face database, target presence, and set size. In Experiment 1, set sizes varied over 1, 2, 4, or 8 items. In Experiments 2 and 3, set sizes varied over 1, 2, 4, or 6 items.

Each trial started with a central fixation cross of random duration between 800 and $1200 \mathrm{~ms}$. The search array was presented for 5 seconds or until the participant responded. Each face stimulus could appear randomly in one of the possible equallyspaced locations on a virtual circle (radius $\sim 6 \mathrm{~cm}$ ) around the fixation point (see Supplemental Figure 1). The target, selected at random from the relevant item set, was present in $50 \%$ of the trials. Distractors were randomly chosen without replacement from the relevant image set such that no face distractor could appear more than once in 
a given trial. Participants were instructed to "press $\mathrm{J}$ if a male [female] is present, press

$F$ if no male [female] is present" and to respond quickly without sacrificing accuracy.

\section{Data analysis}

Search efficiency was measured by the time required to detect the two target types over varying set sizes, and by sensitivity to detect a target as assessed by $\mathrm{d}$ prime. Search rates were determined by estimating with a linear fit the slope relating search set size to response times (RT) for accurate trials. Smaller values (flatter slopes) reflect more efficient search for the target. Because of the complexities of interpreting target-absent search efficiency relative to target-present performance (e.g. Chun \& Wolfe, 1996), we analysed each separately. Sensitivity was assessed by calculating $d-$ prime. To assess biased decision in search we also analysed the response bias ( $\beta$ ). (See Supplemental Materials for details on how each dependent measure was calculated).

Because of the close similarity of the procedures for all three experiments, we conducted analyses combining their results, maximising sensitivity to detect effects of face sex on search efficiency. Specifically, we conducted mixed-design ANOVAs with each dependent measure, with sex of target (within-participants; male, female) and Experiment (between-participants) as factors. These were complemented with one-way Bayesian ANOVAs (assessing the effect of Experiment on the difference between male and female search targets) to distinguish the likelihood of true null effects from inconclusive evidence. Separate analyses per experiment can be found in the Supplemental Materials.

Finally, as a planned test of whether participant gender influenced search asymmetries, using the data from Experiments 1 and 3 (in which male and female participants were represented equally) we ran mixed-design ANOVAs on search slopes and d-prime, with participants' gender and Experiment as between-participants factors, and target sex as a within-participants factor.

\section{Results}

Mean target-present search slopes, and mean d-primes, are reported in Figure 2 and 3 as a function of target sex. Plots of target absent search slopes and criterion (bias) for each experiment are provided in Supplemental Figures 2 and 3, and mean accuracy and response times are reported in Supplemental Table 1.

Target-present RT slopes. The ANOVA on search slopes for accurate targetpresent trials showed a significant effect of target sex $\left(F(1,95)=7.02, p=0.009, \eta p^{2}=\right.$ $0.07)$. Search for female targets $(M=147 \mathrm{~ms} / \mathrm{item}, S D=5)$ was more efficient than search for male targets $(157 \mathrm{~ms} / \mathrm{item}, \mathrm{SD}=5)$. We also found a significant main effect of Experiment $\left(F(2,95)=56.69, p<0.001, \eta p^{2}=0.54\right)$ : visual search was less efficient 
for Experiment 2 compared to Experiment $1(\mathrm{t}(64)=8.13, p<0.001)$ and to Experiment $3(\mathrm{t}(64)=8.65, \mathrm{p}<0.001)$. We did not observe a significant experiment $\mathrm{x}$ target sex interaction $\left(\mathrm{F}(2,95)=0.45, p=0.64, \eta \mathrm{p}^{2}=0.01, \mathrm{BF}_{10}=0.362\right)$.

Target-absent RT slopes. The ANOVA on search slopes for accurate targetabsent trials showed a main effect of search target $\left(F(1,95)=14.78, p<0.001, \eta p^{2}=\right.$ $0.13)$ : reporting the absence of female targets $(M=237 \mathrm{~ms} / \mathrm{item}, \mathrm{SE}=7.3)$ was more efficient than for male targets $(M=254 \mathrm{~ms} /$ item, $S E=7.3)$. There was also a main effect of experiment, $\left.F(2,95)=47.59, p<0.001, \eta p^{2}=0.50\right)$ : visual search was less efficient for Experiment 2 compared to Experiment $1(\mathrm{t}(64)=6.29, p<0.001)$ and to Experiment $3(\mathrm{t}(64)=8.91, p<0.001)$, and search in Experiment 3 for target absent trials was more efficient than Experiment $1(\mathrm{t}(62)=3.02, p=0.004)$. We did not observe a significant interaction between Experiment and target $\operatorname{sex}(F(2,95)=2.22, p=0.11$, $\eta p^{2}=0.04, \mathrm{BF}_{10}=1.22$ ).

Sensitivity (d-prime). The ANOVA on d-prime showed a main effect of target $\left(F(1,95)=19.53, p<0.001, \eta p^{2}=0.17\right)$. Detection of female targets $(M=2.57, S E=$ 2.33) was more accurate than for male targets $(2.33, \mathrm{SE}=0.07)$. We also observed a main effect of Experiment, $\mathrm{F}(2,95)=26.71, p<0.001, \eta p^{2}=0.36$ : detection was less efficient for Experiment 2 compared to Experiment $1(t(64)=7.14, p<0.001)$ and to Experiment $3(t(64)=5.73, p<0.001$. Finally, we did not observe a significant interaction between experiment and target sex, $\left(\mathrm{F}(2,95)=1.82, p=0.17, \Pi p^{2}=0.04\right.$, $\left.\mathrm{BF}_{10}=0.40\right)$.

Bias. The ANOVA on criterion showed a main effect of target $(F(1,95)=36, p<$ $\left.0.001, \eta p^{2}=0.27\right)$, a main effect of experiment $\left(F(1,95)=9.39, p<0.001, \eta p^{2}=0.17\right)$ and a significant target by experiment interaction $\left(F(1,95)=8.53, p<0.001, \eta p^{2}=0.15\right.$, $\left.\mathrm{BF}_{10}=71.77\right)$. Criterion was more conservative in search for female than for male targets (i.e., a male bias) in Experiments 1 and 2 but not in Experiment 3. 
A

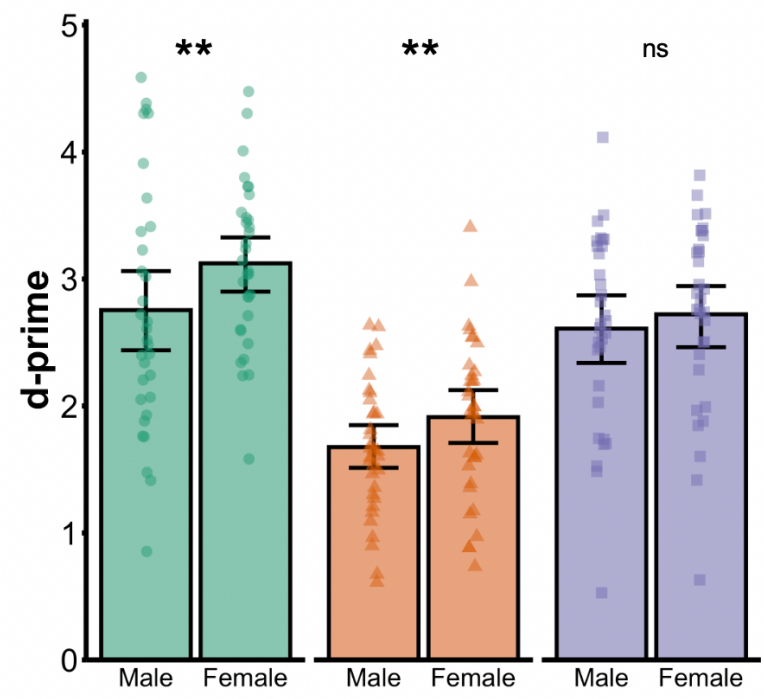

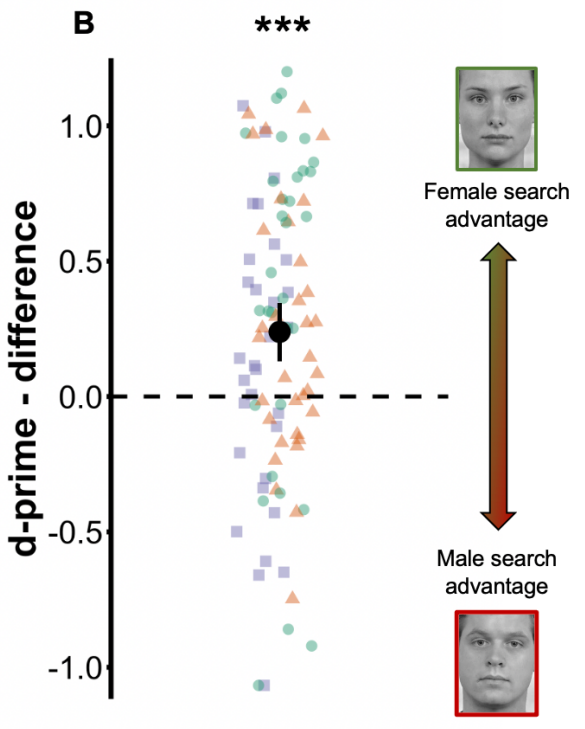

$\square$ Experiment $1 \square$ Experiment $2 \square$ Experiment 3

Figure 2. A. $D$ prime as a function of target type in each experiment. Higher values reflect more efficient search for the target (better sensitivity to the difference between target-present and target-absent trials). B. Point-range plot showing the search asymmetry across experiments as expressed by subtracting male from female targets. Error bars indicate bootstrapped 95\% confidence interval of the mean. Individual points represent means for each individual participant in each experiment. ${ }^{*} p<0.05$; ${ }^{* *} p<$ $0.01 ;{ }^{* * *} p<0.001$

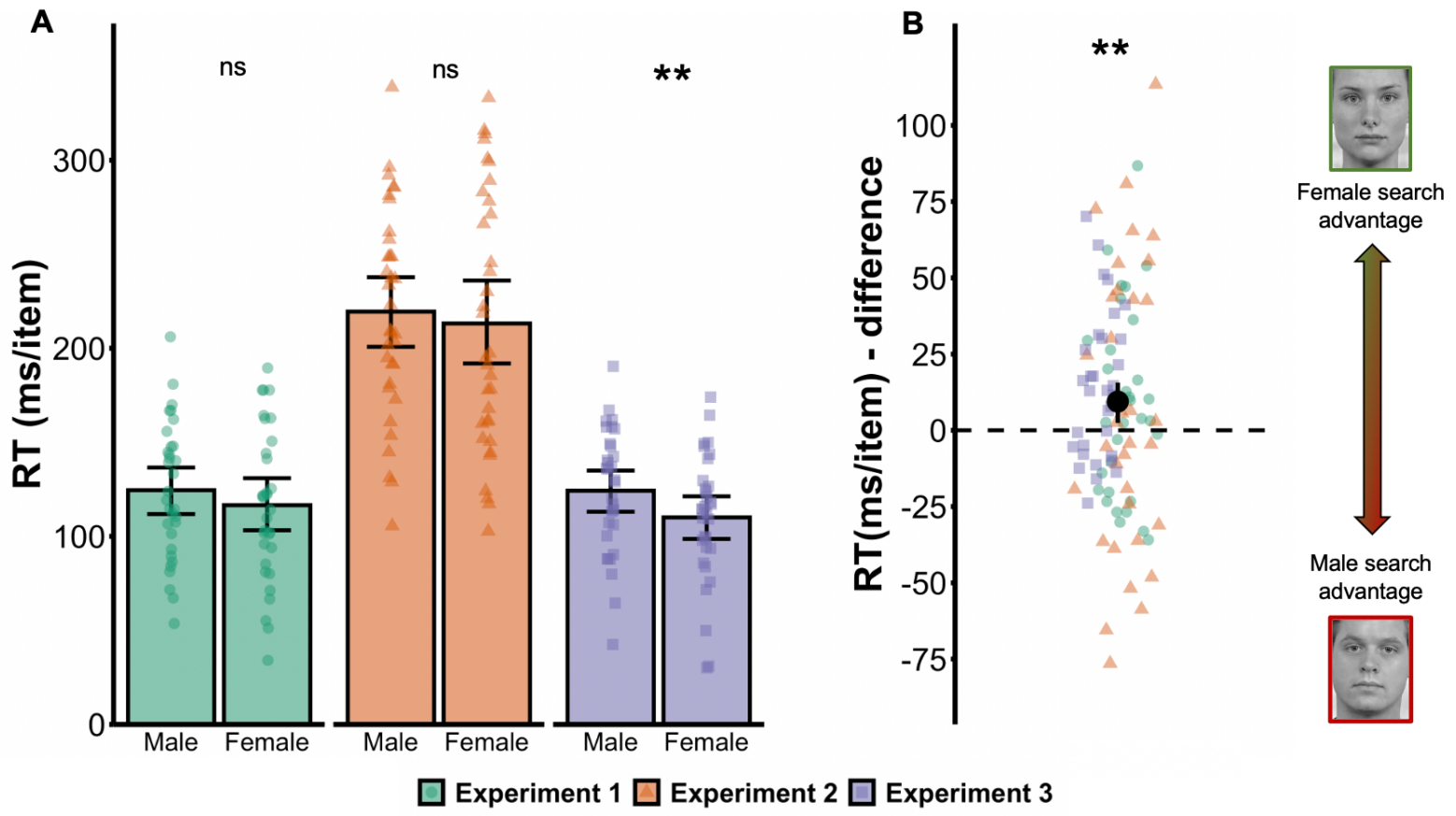


Figure 3. A. RT Search slopes for male and female targets in each experiment. Search slopes were derived from a linear fit to response times on accurate, target-present trials as a function of target type (male or female) and set size. Lower values reflect more efficient visual search (less time required per item to detect the target). B. Point-range plot showing the search asymmetry across experiments as expressed by subtracting female from male targets. Error bars indicate bootstrapped 95\% confidence interval of the mean. Individual points represent means for each individual participant in each experiment. ${ }^{*} p<0.05 ;{ }^{* *} p<0.01 ;{ }^{* * *} p<0.001$

\section{Participant gender}

A mixed-design ANOVA on target-present slopes, with participant gender, experiment, and target sex as factors did not show any significant main effects or interactions involving participant gender (all $p s>0.77$ ). The same analysis on d-prime did not show any significant main effects nor an interaction with participant gender (all $p s>0.20$ ). We conducted a two-tailed Bayesian independent samples t-test assessing effects of participant gender on a search asymmetry index (subtracting male - female target conditions) for both d-prime and target-present slopes. The $\mathrm{BF}_{10}$ for targetpresent slopes was 0.27 , while for d-prime it was 0.28 , indicating that the null hypothesis was at least three times more likely than the alternative hypothesis, suggesting a true null effect of participant's gender on the search asymmetry reported here (Jeffreys, 1961; Lee \& Wagenmakers, 2013).

\section{Stimulus heterogeneity}

We performed post-hoc tests of whether the search benefit for female over male faces is attributable to differences in the homogeneity of the stimuli in the two sets. Search items drawn from a homogenous set will be easier to reject as distractors, compared to a less homogenous set (Duncan \& Humphreys, 1989). As an objective test of homogeneity, we used the GIST approach (Oliva \& Torralba, 2001) to provide a compact yet physiologically plausible description of the low-level visual features of each face. Similarity between a given pair of faces was construed as the Euclidean distance between the two GIST vectors describing those images, and also the correlation between those vectors. For Experiment 1, both similarity measures indicated reliably greater homogenity for male than female faces. For Experiment 2, the distance measure indicated greater homogeneity for male faces, but no reliable difference was shown by the correlation measure. For Experiment 3, female images were reliably more homogenous than male images by both measures (see Supplemental Material for details). 


\section{General Discussion}

We find that observers can detect female faces more efficiently amongst male distractors than vice versa, supporting our hypothesis that coding of sex from the face is polarized rather than balanced. While we did not predict that this advantage would appear variably over experiments in terms of either search rate or detection sensitivity, this variation was not statistically significant, and the search asymmetry was observed over both measures when the data were combined over the three experiments. Further studies could test whether factors such as overall task difficulty, or the use of realistic vs artificial faces, may influence the manifestation of the search asymmetry in measures of speed versus sensitivity. Our findings are unlikely to be due to a single confounding lowlevel variable, owing to the variety of image formats tested. This does not rule out other possible high-level associations between visual properties and facial sex, which may reflect genuinely valid signals that are used by observers. Our analyses of decision criterion effects also replicated (in two experiments) the male "bias" reported in previous studies.

A polarized coding scheme implies that detectors primarily tuned to the standard (male faces) are more strongly activated by the non-standard (female faces) than vice versa. In other words, female faces also activate the male detectors, whereas male faces produce less of an effect on female-tuned detectors. (Note we do not equate "detectors" to single neurons; these could instead constitute neural populations). A corollary, identified by Treisman \& Gormican (1988) for more elementary visual properties, is that the tuning profiles of these detectors may be different, as illustrated schematically in Figure 3. The idea is that tuning of detectors for the standard (male) is broader, such that responses are evoked by a wider range of stimulus types: this in part accommodates the male bias at a decisional level. In comparison, detectors that respond to the unique properties of the non-standard (female) are tuned more narrowly. When the non-standard is a distractor, this generates relatively higher background activity in the detectors for the standard, leading to a difficult target/non-target discrimination. In contrast, when the non-standard is a target, it is more detectable by virtue of the additional unique activity over its more narrowly tuned detectors. This description is consistent with computational analyses of how neural populations (in general) most efficiently code stimuli as a function of their frequency. For example, Ganguli and Simoncelli (2014) argue that more frequently-occurring stimuli will be encoded in the activity of relatively more cells with narrower tuning functions compared to less frequent stimuli, thereby increasing the information content of neural activity patterns. 


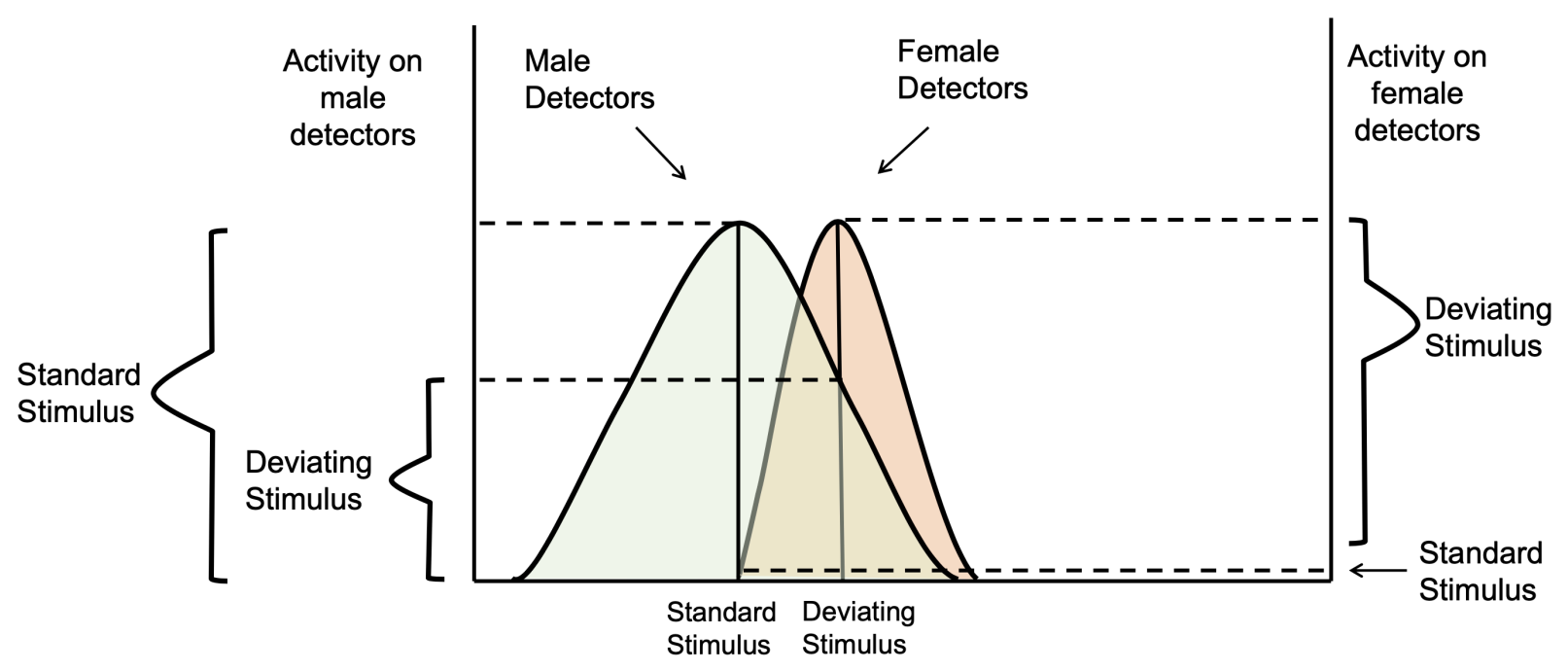

Figure 4. Schematic illustration describing hypothesised perceptual "detectors" that encode sex from facial appearance. Close spacing of peaks reflects high overall similarity of male and female face shapes. Broader tuning for standard (male) than for deviating values (female) accounts in part for an observed "male bias" in that a wider range of stimuli will be judged male than female. A typical female face (peak of orange curve) will elicit some activity on the male detectors and also unique activity on more narrowly tuned female detectors. Conversely, a typical male face (peak of green curve) will activate male detectors and generate little activity on the female detectors. Efficiency of search is governed in part by the ratio of [activity to the target stimulus]:[activity to the distractor stimulus]. Distribution shapes are arbitrary and exaggerated for illustrative purposes. Adapted from Treisman \& Gormican (1988).

What are the underlying sources of this polarised representation? We posit that experience during early visual development, rather than a decision bias with evolutionary origins, may contribute to such representational asymmetries (see also Gandolfo \& Downing, 2020; Quinn et al., 2019 for relevant discussions related to sex; and Furl et al., 2002, for a similar perspective related to race). Visual face representations actively develop within the first year of life (Bhatt et al., 2005; Pascalis et al., 2002). "Sleeper effects" (Maurer et al., 2007) illustrate some of the long-lasting consequences of experience during this early period. For example, infants who are deprived of normal visual input due to congenital cataracts that are corrected within months of birth develop representations of the face that do not, even years later, show the typical hallmarks of configural processing (Le Grand et al., 2001). In Western societies, early caregiving is highly disproportionately provided by adult females (Rennels \& Davis, 2008; Sugden et al., 2014; United Kingdom Survey of Childcare and Early Years Providers, 2018), so it follows that the input to early developing face 
representations is typically mostly from females. This manifests in infancy as an attentional bias for female faces (Ramsey et al., 2005; Righi et al., 2014; see also Rennels et al., 2017). For example, infants aged 3-4 months looked longer at female faces when they were paired together with male faces (Rennels et al., 2017); the preference depended on the participants having females as primary caregivers, reversing in a sample of infants raised primarily by male caregivers.

Our proposal is that unbalanced developmental visual experience with female faces results in lasting denser neural encoding of female faces relative to male faces. In the terms of Treisman and Gormican's (Treisman \& Gormican, 1988) analysis, equates to female "detectors" being more narrowly tuned to their preferred stimuli compared to male "detectors" (Figure 4) which in turn generates asymmetric search performance for female faces. This proposal does not exclude the influence of other aspects of visual experience on face perception (such as during adolescence (Leder et al., 2003; Picci \& Scherf, 2016)). Although they are reported in other kinds of face tasks (e.g. Herlitz \& Lovén, 2013; Lovén et al., 2011; Scherf et al., 2017), we did not find an influence of participant gender on search asymmetries in the two experiments for which gender was balanced, in line with previous findings for bodies (Gandolfo \& Downing, 2020).

We tested for objective differences between our male and female stimulus sets in their homogeneity that could impact search performance. In Experiment 1 the male stimuli were more homogenous than the females, but in Experiment 3 this pattern was reversed. (The results for Experiment 2 were inconsistent; silhouette profiles lack texture and may be poorly suited to a GIST description). While in future replications it will be useful to closely match stimulus sets on objective or subjective measures of homogeneity, we conclude that objective differences in homogeneity do not fully account for the search asymmetry reported here.

Previously (Gandolfo \& Downing, 2020), we used the same visual search strategy to show that for body shape a male bias (Gaetano et al., 2016; Johnson et al., 2012), reflects a deeper asymmetry of perceptual encoding. As here, we argued that these findings reflect a representation of body shape that encodes female body form by reference to a male default. The agreement between faces and bodies is consistent with the developmental experience hypothesis outlined above, although it may also be consistent with others. An open question is whether these analogous findings over faces and bodies reflect a single abstract sex representation, generalising over faceand body-specific mechanisms (see Ghuman et al., 2010; Palumbo et al., 2015), or instead reflects a common property of distinct domain-specific analysers. Furthermore, our experience-based account would predict similar polarised coding of sex cues in other dimensions such as body motion patterns, or even voice properties, provided there is evidence that the relevant mechanisms are actively developing during an period in which the "diet" of social experience is typically skewed towards females. 
As part of the wider literature on sex and gender perception, our results reveal some of the perceptual processes that rapidly categorise social stimuli, leading to downstream effects on social behaviour (e.g. Hehman et al., 2014). As such, they contribute to broader efforts to understand the interplay between perception, categorisation, judgment, stereotypes, and attitudes that takes place constantly in daily life (Freeman \& Ambady, 2011; Macrae \& Quadflieg, 2010; Todorov, 2017).

\section{Data availability statement}

The datasets generated during and/or analysed during the current study are available in the OSF repository, https://osf.io/ucq2g/

\section{Declaration of competing interests}

None.

\section{Acknowledgments}

Marco Gandolfo collected the data. Both Marco Gandolfo and Paul Downing conceived the research and wrote the manuscript. We are grateful to the Social Cognition and Neuroscience group at Bangor University, and specifically to Lara Maister, Surya Gayet and Qiu Han for ongoing discussions and feedback. Ionela Bara contributed to data collection and stimulus creation for Experiment 3. 


\section{References}

Adams, R. B., Ambady, N., Nakayama, K., \& Shimojo, S. (Eds.). (2010). The science of social vision. Oxford University Press.

10.1093/acprof:oso/9780195333176.001.0001

Afraz, A., Pashkam, M. V., \& Cavanagh, P. (2010). Spatial heterogeneity in the perception of face and form attributes. Current Biology, 20(23), 2112-2116. https://doi.org/10.1016/j.cub.2010.11.017

Armann, R., \& Bülthoff, I. (2012). Male and female faces are only perceived categorically when linked to familiar identities-and when in doubt, he is a male. Vision Research, 63, 69-80. https://doi.org/10.1016/j.visres.2012.05.005

Baudouin, J. Y., \& Humphreys, G. W. (2006). Configural information in gender categorisation. Perception, 35(4), 531-540. https://doi.org/10.1068/p3403

Becker, D. V., Anderson, U. S., Mortensen, C. R., Neufeld, S. L., \& Neel, R. (2011). The face in the crowd effect unconfounded: Happy faces, not angry faces, are more efficiently detected in single-and multiple-target visual search tasks. Journal of Experimental Psychology: General, 140(4), 637.

https://doi.org/10.1037/a0024060

Becker, D. V., \& Rheem, H. (2020). Searching for a face in the crowd: Pitfalls and unexplored possibilities. Attention, Perception, \& Psychophysics, 1-11. https://doi.org/10.3758/s13414-020-01975-7

Berry, D. S. (1991). Child and adult sensitivity to gender information in patterns of facial motion. Ecological Psychology, 3(4), 349-366. https://doi.org/10.1207/s15326969eco0304_3 
Bestelmeyer, P. E., Jones, B. C., DeBruine, L. M., Little, A. C., Perrett, D. I., Schneider, A., \& Conway, C. A. (2008). Sex-contingent face aftereffects depend on perceptual category rather than structural encoding. Cognition, 107(1), 353-365. https://doi.org/10.1016/j.cognition.2007.07.018

Bhatt, R. S., Bertin, E., Hayden, A., \& Reed, A. (2005). Face processing in infancy: Developmental changes in the use of different kinds of relational information. Child Development, 76(1), 169-181. https://doi.org/10.1111/j.14678624.2005.00837.x

Boisferon, A., Dupierrix, E., Uttley, L., DeBruine, L. M., Jones, B. C., \& Pascalis, O. (2019). Sex categorization of faces: The effects of age and experience. IPerception, 10(1), 2041669519830414. https://doi.org/10.1177\%2F2041669519830414

Brainard, D. H., \& Vision, S. (1997). The psychophysics toolbox. Spatial Vision, 10(4), 433-436. https://psycnet.apa.org/doi/10.1163/156856897X00357

Brown, E., \& Perrett, D. I. (1993). What gives a face its gender? Perception, 22(7), 829840. https://doi.org/10.1068\%2Fp220829

Bruce, V., Burton, A. M., Hanna, E., Healey, P., Mason, O., Coombes, A., \& Linney, A. (1993). Sex discrimination: How do we tell the difference between male and female faces? Perception, 22(2), 131-152. https://doi.org/10.1068\%2Fp220131

Bruce, V., \& Langton, S. (1994). The use of pigmentation and shading information in recognising the sex and identities of faces. Perception, 23(7), 803-822. https://doi.org/10.1068/p230803 
Calvo, M. G., \& Lundqvist, D. (2008). Facial expressions of emotion (KDEF): Identification under different display-duration conditions. Behavior Research Methods, 40(1), 109-115. https://doi.org/10.3758/BRM.40.1.109

Carter, W. A. (1944). Nicknames and minority groups. Phylon, 5(3), 241-245. https://doi.org/10.2307/271306

Chun, M. M., \& Wolfe, J. M. (1996). Just say no: How are visual searches terminated when there is no target present?. Cognitive psychology, 30(1), 39-78.

Davidenko, N. (2007). Silhouetted face profiles: A new methodology for face perception research. Journal of Vision, 7(4), 6-6. https://doi.org/10.1167/7.4.6

Davidenko, N., Remus, D. A., \& Grill-Spector, K. (2012). Face-likeness and image variability drive responses in human face-selective ventral regions. Human Brain Mapping, 33(10), 2334-2349. https://doi.org/10.1002/hbm.21367

De Gutis, J., Chatterjee, G., Mercado, R. J., \& Nakayama, K. (2012). Face gender recognition in developmental prosopagnosia: Evidence for holistic processing and use of configural information. Visual Cognition, 20(10), 1242-1253. https://doi.org/10.1080/13506285.2012.744788

Duncan, J., \& Humphreys, G. W. (1989). Visual search and stimulus similarity. Psychological Review, 96(3), 433. https://doi.org/10.1037/0033-295x.96.3.433

Dupuis-Roy, N., Fortin, I., Fiset, D., \& Gosselin, F. (2009). Uncovering gender discrimination cues in a realistic setting. Journal of Vision, 9(2), 10-10. https://doi.org/10.1167/9.2.10 
Eagly, A. H., \& Mladinic, A. (1989). Gender stereotypes and attitudes toward women and men. Personality and Social Psychology Bulletin, 15(4), 543-558. https://doi.org/10.1177/0146167289154008

Enns, J. T., \& Rensink, R. A. (1990). Influence of scene-based properties on visual search. Science, 247(4943), 721-723. https://doi.org/10.1126/science.2300824

Enns, J. T., \& Rensink, R. A. (1991). Preattentive recovery of three-dimensional orientation from line drawings. Psychological Review, 98(3), 335. https://psycnet.apa.org/doi/10.1037/0033-295X.98.3.335

Faghel-Soubeyrand, S., Dupuis-Roy, N., \& Gosselin, F. (2019). Inducing the use of right eye enhances face-sex categorization performance. Journal of Experimental Psychology: General, 148(10), 1834. https://doi.org/10.1037/xge0000542

Freeman, J. B., \& Ambady, N. (2011). A dynamic interactive theory of person construal. Psychological Review, 118(2), 247-279. https://doi.org/10.1037/a0022327

Furl, N., Phillips, P. J., \& O'Toole, A. J. (2002). Face recognition algorithms and the other-race effect: computational mechanisms for a developmental contact hypothesis. Cognitive science, 26(6), 797-815.

Gaetano, J., Van Der Zwan, R., Oxner, M., Hayward, W. G., Doring, N., Blair, D., \& Brooks, A. (2016). Converging evidence of ubiquitous male bias in human sex perception. PloS One, 11(2), e0148623. https://doi.org/10.1371/journal.pone.0148623

Gandolfo, M., \& Downing, P. E. (2020). Asymmetric visual representation of sex from human body shape. Cognition, 205, 104436. https://doi.org/10.1016/j.cognition.2020.104436 
Ghuman, A. S., McDaniel, J. R., \& Martin, A. (2010). Face adaptation without a face. Current Biology, 20(1), 32-36. https://doi.org/10.1016/j.cub.2009.10.077

Goeleven, E., De Raedt, R., Leyman, L., \& Verschuere, B. (2008). The Karolinska directed emotional faces: A validation study. Cognition and Emotion, 22(6), 1094-1118. https://doi.org/10.1080/02699930701626582

Graf, A. B., \& Wichmann, F. A. (2002). Gender classification of human faces. In International Workshop on Biologically Motivated Computer Vision (pp. 491500). Springer. https://doi.org/10.1007/3-540-36181-2_49

Haselton, M. G., \& Buss, D. M. (2000). Error management theory: A new perspective on biases in cross-sex mind reading. Journal of Personality and Social Psychology, 78(1), 81. https://doi.org/10.1037/0022-3514.78.1.81

Haselton, M. G., Nettle, D., \& Murray, D. R. (2015). The evolution of cognitive bias. The Handbook of Evolutionary Psychology, 1-20. https://doi.org/10.1002/9781119125563.evpsych241

Hehman, E., Carpinella, C. M., Johnson, K. L., Leitner, J. B., \& Freeman, J. B. (2014). Early processing of gendered facial cues predicts the electoral success of female politicians. Social Psychological and Personality Science, 5(7), 815-824. https://doi.org/10.1177/1948550614534701

Herlitz, A., \& Lovén, J. (2013). Sex differences and the own-gender bias in face recognition: A meta-analytic review. Visual Cognition, 21(9-10), 1306-1336. https://doi.org/10.1080/13506285.2013.823140 
Hulleman, J., Te Winkel, W., \& Boselie, F. (2000). Concavities as basic features in visual search: Evidence from search asymmetries. Perception \& Psychophysics, 62(1), 162-174. https://doi.org/10.3758/bf03212069

Ito, T. A., \& Urland, G. R. (2003). Race and gender on the brain: Electrocortical measures of attention to the race and gender of multiply categorizable individuals. Journal of Personality and Social Psychology, 85(4), 616. https://doi.org/10.1037/0022-3514.85.4.616

Jeffreys, H. (1961). The Theory of Probability. OUP Oxford.

Johnson, K. L., lida, M., \& Tassinary, L. G. (2012). Person (mis)perception: Functionally biased sex categorization of bodies. Proceedings of the Biological Sciences, 279(1749), 4982-4989. https://doi.org/10.1098/rspb.2012.2060

Kristjánsson, Á., \& Tse, P. U. (2001). Curvature discontinuities are cues for rapid shape analysis. Perception \& Psychophysics, 63(3), 390-403. https://doi.org/10.3758/BF03194407

Langner, O., Dotsch, R., Bijlstra, G., Wigboldus, D. H., Hawk, S. T., \& Van Knippenberg, A. D. (2010). Presentation and validation of the Radboud Faces Database. Cognition and Emotion, 24(8), 1377-1388. https://doi.org/10.1080/02699930903485076

Le Grand, R., Mondloch, C. J., Maurer, D., \& Brent, H. P. (2001). Early visual experience and face processing. Nature, 410(6831), 890-890. https://doi.org/10.1038/35073749

Leder, H., Schwarzer, G., \& Langton, S. (2003). Development of face processing in early adolescence. 
Lee, M. D., \& Wagenmakers, E.-J. (2013). Bayesian cognitive modeling: A practical course (pp. xiii, 264). Cambridge University Press. https://doi.org/10.1017/CBO9781139087759

Little, A. C., Burt, D. M., Penton-Voak, I. S., \& Perrett, D. I. (2001). Self-perceived attractiveness influences human female preferences for sexual dimorphism and symmetry in male faces. Proceedings of the Royal Society of London. Series B: Biological Sciences, 268(1462), 39-44. https://doi.org/10.1098\%2Frspb.2000.1327

Lovén, J., Herlitz, A., \& Rehnman, J. (2011). Women's own-gender bias in face recognition memory. Experimental psychology. 10.1027/1618-3169/a000100

Macrae, C. N., \& Martin, D. (2007). A boy primed Sue: Feature-based processing and person construal. European Journal of Social Psychology, 37(5), 793-805. https://doi.org/10.1002/ejsp.406

Macrae, C. N., \& Quadflieg, S. (2010). Perceiving people. In S. T. Fiske, D. T. Gilbert, \& G. Lindzey (Eds.), Handbook of social psychology (pp. 428-463). John Wiley \& Sons, Inc. https://psycnet.apa.org/doi/10.1002/9780470561119.socpsy001012

Maurer, D., Mondloch, C. J., \& Lewis, T. L. (2007). Sleeper effects. Developmental Science, 10(1), 40-47. https://doi.org/10.1111/j.1467-7687.2007.00562.x

Neisser, U. (1963). Decision-time without reaction-time: Experiments in visual scanning. The American Journal of Psychology, 76(3), 376-385. https://doi.org/10.2307/1419778 
Nestor, A., \& Tarr, M. J. (2008). Gender recognition of human faces using color. Psychological Science, 19(12), 1242-1246. https://doi.org/10.1111/j.14679280.2008.02232.x

Oliva, A., \& Torralba, A. (2001). Modeling the shape of the scene: A holistic representation of the spatial envelope. International Journal of Computer Vision, 42(3), 145-175. https://doi.org/10.1023/A:1011139631724

Oosterhof, N. N., \& Todorov, A. (2008). The functional basis of face evaluation. Proceedings of the National Academy of Sciences, 105(32), 11087-11092. https://doi.org/10.1073/pnas.0805664105

Palumbo, R., D’Ascenzo, S., \& Tommasi, L. (2015). Cross-category adaptation: Exposure to faces produces gender aftereffects in body perception. Psychological Research, 79(3), 380-388. https://doi.org/10.1007/s00426-0140576-2

Pascalis, O., De Haan, M., \& Nelson, C. A. (2002). Is face processing species-specific during the first year of life? Science, 296(5571), 1321-1323. https://doi.org/10.1126/science.1070223

Pelli, D. G., \& Vision, S. (1997). The VideoToolbox software for visual psychophysics: Transforming numbers into movies. Spatial Vision, 10, 437-442. https://doi.org/10.1163/156856897X00366

Perrett, D. I., Lee, K. J., Penton-Voak, I., Rowland, D., Yoshikawa, S., Burt, D. M., \& Akamatsu, S. (1998). Effects of sexual dimorphism on facial attractiveness. Nature, 394(6696), 884-887. https://doi.org/10.1038/29772 
Picci, G., \& Scherf, K. S. (2016). From caregivers to peers: Puberty shapes human face perception. Psychological Science, 27(11), 1461-1473. https://doi.org/10.1177/0956797616663142

Proctor, R. W., \& Cho, Y. S. (2006). Polarity correspondence: A general principle for performance of speeded binary classification tasks. Psychological Bulletin, 132(3), 416. https://doi.org/10.1037/0033-2909.132.3.416

Quinn, P. C., Lee, K., \& Pascalis, O. (2019). Face processing in infancy and beyond: The case of social categories. Annual Review of Psychology, 70, 165-189. https://doi.org/10.1146/annurev-psych-010418-102753

Rajsic, J., Carlisle, N. B., \& Woodman, G. F. (2020). What not to look for: Electrophysiological evidence that searchers prefer positive templates. Neuropsychologia, 140, 107376. https://doi.org/10.1016/j.neuropsychologia.2020.107376

Ramsey, J. L., Langlois, J. H., \& Marti, N. C. (2005). Infant categorization of faces: Ladies first. Developmental Review, 25(2), 212-246. https://doi.org/10.1016/j.dr.2005.01.001

Rennels, J. L., \& Davis, R. E. (2008). Facial experience during the first year. Infant Behavior and Development, 31(4), 665-678. https://doi.org/10.1016/j.infbeh.2008.04.009

Rennels, J. L., Juvrud, J., Kayl, A. J., Asperholm, M., Gredebäck, G., \& Herlitz, A. (2017). Caregiving experience and its relation to perceptual narrowing of face gender. Developmental Psychology, 53(8), 1437. https://doi.org/10.1037/dev0000335 
Righi, G., Westerlund, A., Congdon, E. L., Troller-Renfree, S., \& Nelson, C. A. (2014). Infants' experience-dependent processing of male and female faces: Insights from eye tracking and event-related potentials. Developmental Cognitive Neuroscience, 8, 144-152. https://doi.org/10.1016/j.dcn.2013.09.005

Russell, R. (2009). A sex difference in facial contrast and its exaggeration by cosmetics. Perception, 38(8), 1211-1219. https://doi.org/10.1068/p6331

Russell, R., Kramer, S. S., \& Jones, A. L. (2017). Facial contrast declines with age but remains sexually dimorphic throughout adulthood. Adaptive Human Behavior and Physiology, 3(4), 293-303. https://doi.org/10.1007/s40750-017-0068-x

Scherf, K. S., Elbich, D. B., \& Motta-Mena, N. V. (2017). Investigating the influence of biological sex on the behavioral and neural basis of face recognition. Eneuro, 4(3). https://doi.org/10.1523/ENEURO.0104-17.2017

Schyns, P. G., Bonnar, L., \& Gosselin, F. (2002). Show me the features! Understanding recognition from the use of visual information. Psychological Science, 13(5), 402-409. https://doi.org/10.1111/1467-9280.00472

Skrypnek, B. J., \& Snyder, M. (1982). On the self-perpetuating nature of stereotypes about women and men. Journal of Experimental Social Psychology, 18(3), 277291. https://doi.org/10.1016/0022-1031(82)90054-3

Stroessner, S. J. (1996). Social categorization by race or sex: Effects of perceived nonnormalcy on response times. Social Cognition, 14(3), 247-276. https://psycnet.apa.org/doi/10.1521/soco.1996.14.3.247

Sugden, N. A., Mohamed-Ali, M. I., \& Moulson, M. C. (2014). I spy with my little eye: Typical, daily exposure to faces documented from a first-person infant 
perspective. Developmental Psychobiology, 56(2), 249-261. https://doi.org/10.1002/dev.21183

Sun, J., \& Perona, P. (1996). Early computation of shape and reflectance in the visual system. Nature, 379(6561), 165-168. https://doi.org/10.1038/379165a0

Sun, J. Y., \& Perona, P. (1996). Preattentive perception of elementary threedimensional shapes. Vision Research, 36(16), 2515-2529. https://doi.org/10.1016/0042-6989(95)00336-3

Todorov, A. (2017). Face value. Princeton University Press.

Tottenham, N., Tanaka, J. W., Leon, A. C., McCarry, T., Nurse, M., Hare, T. A., \& Nelson, C. (2009). The NimStim set of facial expressions: Judgments from untrained research participants. Psychiatry Research, 168(3), 242-249. https://doi.org/10.1016/j.psychres.2008.05.006

Treisman, A., \& Gormican, S. (1988). Feature analysis in early vision: Evidence from search asymmetries. Psychological Review, 95(1), 15. https://doi.org/10.1037/0033-295x.95.1.15

Treisman, A., \& Souther, J. (1985). Search asymmetry: A diagnostic for preattentive processing of separable features. Journal of Experimental Psychology: General, 114(3), 285. https://doi.org/10.1037//0096-3445.114.3.285

Tskhay, K. O., \& Rule, N. O. (2016). People automatically extract infants' sex from faces. Journal of Nonverbal Behavior, 40(4), 247-254. https://doi.org/10.1007/s10919-016-0235-y 
United Kingdom Survey of Childcare and Early Years Providers. (2018).

https://www.gov.uk/government/statistics/childcare-and-early-years-providerssurvey-2018

Wardle, S. G., Paranjabe, S., Taubert, J., \& Baker, C. I. (2022). Illusory faces are more likely to be perceived as male than female. Proceedings of the National Academy of Sciences, 119(5). https://doi.org/10.1073/pnas.2117413119

Watson, T. L., Otsuka, Y., \& Clifford, C. W. G. (2016). Who are you expecting? Biases in face perception reveal prior expectations for sex and age. Journal of Vision, 16(3), 5-5. https://doi.org/10.1167/16.3.5

Webster, M. A., Kaping, D., Mizokami, Y., \& Duhamel, P. (2004). Adaptation to natural facial categories. Nature, 428(6982), 557-561. https://doi.org/10.1038/nature02420

Webster, M. A., \& MacLeod, D. I. (2011). Visual adaptation and face perception. Philosophical Transactions of the Royal Society B: Biological Sciences, 366(1571), 1702-1725. https://doi.org/10.1098\%2Frstb.2010.0360

Wild, H. A., Barrett, S. E., Spence, M. J., O'Toole, A. J., Cheng, Y. D., \& Brooke, J. (2000). Recognition and sex categorization of adults' and children's faces: Examining performance in the absence of sex-stereotyped cues. Journal of Experimental Child Psychology, 77(4), 269-291.

https://doi.org/10.1006/jecp.1999.2554

Willenbockel, V., Sadr, J., Fiset, D., Horne, G. O., Gosselin, F., \& Tanaka, J. W. (2010). Controlling low-level image properties: The SHINE toolbox. Behavior Research Methods, 42(3), 671-684. https://doi.org/10.3758/BRM.42.3.671 
Yamaguchi, M. K., Hirukawa, T., \& Kanazawa, S. (2013). Judgment of gender through facial parts. Perception, 42(11), 1253-1265. https://doi.org/10.1068/p240563

Zhao, M., \& Hayward, W. G. (2010). Holistic processing underlies gender judgments of faces. Attention, Perception, \& Psychophysics, 72(3), 591-596. https://doi.org/10.3758/APP.72.3.591 